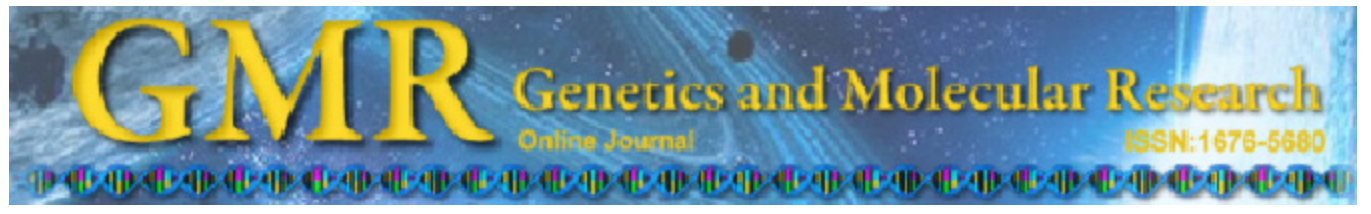

\title{
Analysis of diversity and relationships among orchardgrass (Dactylis glomerata L.) accessions using start codon-targeted markers
}

\author{
L.F. Jiang ${ }^{1,2}$, X. Qi ${ }^{3}$, X.Q. Zhang ${ }^{1}$, L.K. Huang ${ }^{1}$, X. Ma ${ }^{1}$ and W.G. Xie ${ }^{4}$ \\ ${ }^{1}$ Department of Grassland Science, Animal Science and Technology College, \\ Sichuan Agricultural University, Ya'an, Sichuan, China \\ ${ }^{2}$ Department of Livestock Production Station, Dianjiang, Chongqing, China \\ ${ }^{3}$ National Animal Husbandry Service of Ministry of Agriculture, Beijing, China \\ ${ }^{4}$ The State Key Laboratory of Grassland Agro-Ecosystems, \\ College of Pastoral Agriculture Science and Technology, \\ Lanzhou University, Lanzhou, China \\ Corresponding author: X.Q. Zhang \\ E-mail: zhangxq@sicau.edu.cn
}

Genet. Mol. Res. 13 (2): 4406-4418 (2014)

Received October 8, 2013

Accepted February 25, 2014

Published June 11, 2014

DOI http://dx.doi.org/10.4238/2014.June.11.4

ABSTRACT. Orchardgrass, or cocksfoot, is an important perennial
forage grass worldwide. The comprehensive understanding of
orchardgrass accessions will benefit germplasm collection and
breeding progress, and it will enhance efforts to improve forage yield
and quality. Therefore, 24 novel, simple, polymorphic, and reliable
start codon-targeted (SCoT) markers were used to analyze the diversity
and genetic relationships among 95 orchardgrass accessions. In total,
273 polymorphic bands were detected with an average of 11.4 bands
per primer. The average polymorphic rate for the species was $83.4 \%$,
suggesting a high discriminating ability of the SCoT technique for
orchardgrass. The molecular variance analysis revealed that 69.13 and
$30.87 \%$ of variation resided within and among groups, respectively,
demonstrating that the orchardgrass germplasms had a higher level of 
genetic diversity within groups than among geographical regions and distributions. The distinct geographical divergence of orchardgrass was revealed between North America and Oceania. The unweighted pairgroup method with arithmetic mean dendrogram revealed a separation of 7 main clusters between 95 accessions according to the geographical origin. Furthermore, each cluster was divided into subgroups mainly according to the origin of its state. The genetic divergence of orchardgrass might be influenced by the ecogeographical conditions, climatic types, breeding systems and gene flow with variations in cultures, bird migration, and breeder selection. These results could facilitate orchardgrass germplasm collection, management, and breeding worldwide.

Key words: Dactylis glomerata; Start codon-targeted markers; Genetic diversity

\section{INTRODUCTION}

Dactylis is an allogamous and variable monospecific genus that belongs to the Poaceae family (Lindner and Garcia, 1997) and consists of diploid $(2 \mathrm{n}=2 \mathrm{x}=14)$, tetraploid ( $2 \mathrm{n}$ $=4 \mathrm{x}=28)$, and hexaploid $(2 \mathrm{n}=6 \mathrm{x}=42)$ populations and subspecies and the single species Dactylis glomerata is known as orchardgrass or cocksfoot (Bushman et al., 2011; Stewart and Ellison, 2011). Orchardgrass is an economically important and extensively used cool-season forage grass in China and in many other countries with temperate and cold climates (Sanada et al., 2010; Xie et al., 2012). It has been widely used as forage on nearly every continent because of its high yield, good nutrition, adaptability, and shade tolerance (Jafari and Naseri, 2007; Sanada et al., 2007; Xie et al., 2010). Orchardgrass is one of the top 4 perennial forage grasses grown in North America, Oceania, Europe, and Asia (Lindner and Garcia, 1997; Gauthier et al., 1998; Hirata et al., 2011), and it plays an important role in the livestock industry and in the sustainable development of environments worldwide.

Because of its economic importance as a perennial forage grass, a comprehensive understanding of genetic diversity and variation among cultivars and wild and cultivated accessions will benefit germplasm collection and breeding progress, and it will enhance efforts to improve forage yield, quality, and other value-added traits (Xie et al., 2010; Bushman et al., 2011). Genetic diversity in crop species can be determined using morphological and agronomic characteristics as well as biochemical and DNA marker analysis (Liu, 1997). However, physiological and morphological traits are subjective and quantitative in practice, and they can be affected by environmental conditions and the experience of evaluators (Roldán-Ruiz et al., 2001; Degani et al., 2003; Bolaric et al., 2005). In recent years, a number of molecular markers have been employed in orchardgrass for genetic diversity evaluation, genetic mapping, and quantitative trait locus analysis. These types of molecular techniques included random amplified polymorphic DNA (RAPD) (Kölliker et al., 1999; Tuna et al., 2004), amplified fragment length polymorphism (AFLP) (Reeves et al., 1998; Peng et al., 2008), inter-simple sequence repeat (ISSR) (Zeng et al., 2006), sequence-related amplified polymorphism (Zeng et al., 2008; Xie et al., 2011), simple sequence repeats (SSRs) (Hirata et al., 2011; Xie et al., 
2011, 2012), and expressed sequence tag-SSRs (Xie et al., 2010; Bushman et al., 2011). These marker systems are useful for biodiversity analyses, phylogenetic studies, germplasm management, cultivar identification, and other applications (Semagn et al., 2006; Luo et al., 2010). However, the investigation of genetic diversity by molecular markers for breeding purposes should be based on functionally characterized genes or targeted genes (Andersen and Lübberstedt, 2003) because these markers may reflect functional polymorphisms indirectly.

Of these molecular markers, start codon-targeted (SCoT) polymorphism is a novel, simple, highly polymorphic, and reliable gene-targeted marker technique that is based on a single primer amplification reaction, which was designed using a single primer according to the conservation of the ATG translation start site and flanking sequences in plant genes (Collard and Mackill, 2009; Luo et al., 2010; Guo et al., 2012). In addition, the SCoT technique is convenient for marker-assisted breeding because it effectively produces markers that are linked to traits. Moreover, SCoT markers can be used as an effective complementary method to ISSR and RAPD (Guo et al., 2012). During the last 4 years, this technique was successfully used in studies of genetic diversity in plants and showed high polymorphic information. However, little has been reported on the use of SCoT markers for genetic diversity analysis in orchardgrass.

Recently, 95 orchardgrass accessions from 21 countries and 7 geographical regions were collected to evaluate both the level of genetic diversity and the distribution of its variation in orchardgrass by SCoT markers. Therefore, the primary goals of this study were the following: a) examine the effectiveness of these SCoT markers for genetic diversity analysis of orchardgrass accessions, b) study genetic relationships among 95 orchardgrass accessions originating from various geographic regions, and c) investigate the genetic variation within and among geographical regions. These results could facilitate orchardgrass germplasm collection, management, and breeding worldwide.

\section{MATERIAL AND METHODS}

\section{Plant materials and DNA extraction}

Ninety-five orchardgrass accessions comprising cultivars and cultivated and wild materials collected from 21 countries and 7 geographical regions were analyzed by means of SCoT markers. They were obtained from the United States Department of AgricultureAgricultural Research Service and Sichuan Agricultural University, China. Among these accessions, 43 Chinese [northern China (NC) and southern China (SC)] accessions were from Chongqing, Guizhou, Hubei, Jiangxi, Gansu, Sichuan, Xinjiang, and Yunnan; other accessions were from Europe [western Europe (WE), central Europe (CE), and northern Europe (NE)], North America (NA), and Oceania (OC), which represent the main distribution regions of orchardgrass worldwide (Table 1, Figure 1).

Each accession was represented by 25 plants, and $100 \mathrm{mg}$ fresh young leaves from each plant was used to create a pool. Genomic DNA was extracted from the samples collected using the Plant Genomic DNA kit (Tiangen ${ }^{\circledR}$, China) according to the manufacturer protocol. The DNA quality and concentration were confirmed by electrophoresis on $0.8 \%$ agarose gels and NanoDrop (ND) 1000 ultraviolet and visible spectrophotometry (ND Technologies, Inc., USA). The genomic DNA samples were diluted to $10 \mathrm{ng} / \mu \mathrm{L}$ and stored at $4^{\circ} \mathrm{C}$ for use. 
Table 1. List of 95 orchardgrass (Dactylis glomerata L.) accessions.

\begin{tabular}{|c|c|c|c|c|c|c|c|}
\hline Code & Accession No & Geographic source (Code) & Status & Code & Accession No & Geographic source (Code) & Status \\
\hline 1 & 01819 & Denmark (NE) & Wild & 48 & 01473 & Australia (OC) & Wild \\
\hline 2 & 01820 & Denmark (NE) & Wild & 49 & 01475 & Australia (OC) & Wild \\
\hline 3 & 01822 & Denmark (NE) & Wild & 50 & PI285099 & Australia (OC) & Cultivar \\
\hline 4 & 01824 & Denmark (NE) & Wild & 51 & PI469234 & New Zealand (OC) & Cultivar \\
\hline 5 & $79-14$ & Denmark (NE) & Wild & 52 & Wana & New Zealand (OC) & Cultivar \\
\hline 6 & $79-15$ & Denmark (NE) & Wild & 53 & 01472 & Chongqing, China (SC) & Cultivated \\
\hline 7 & Anba & Denmark (NE) & Cultivar & 54 & 2006-1 & Chongqing, China (SC) & Wild \\
\hline 8 & PI345603 & Krasnodar, Russia (NE) & Cultivar & 55 & $2006-5$ & Chongqing, China (SC) & Wild \\
\hline 9 & PI381630 & Sweden (NE) & Cultivar & 56 & Hongchiba & Wuxi, Chongqing, China (SC) & Wild \\
\hline 10 & 01993 & Sweden (NE) & Wild & 57 & 01175 & Dushan, Guizhou, China (SC) & Wild \\
\hline 11 & 01994 & Sweden (NE) & Wild & 58 & $01-101$ & Bijie, Guizhou, China (SC) & Wild \\
\hline 12 & 01995 & Sweden (NE) & Wild & 59 & $01-102$ & Guizhou, China (SC) & Wild \\
\hline 13 & 01996 & Sweden (NE) & Wild & 60 & $02-102$ & Guizhou, China (SC) & Wild \\
\hline 14 & 01997 & Sweden (NE) & Wild & 61 & $02-103$ & Guizhou, China (SC) & Wild \\
\hline 15 & 01998 & Sweden (NE) & Wild & 62 & $02-104$ & Guizhou, China (SC) & Wild \\
\hline 16 & 01999 & Sweden (NE) & Wild & 63 & $79-9$ & Lushan, Jiangxi, China (SC) & Cultivated \\
\hline 17 & 02684 & United Kingdom (NE) & Wild & 64 & $01-103$ & Sichuan, China (SC) & Cultivated \\
\hline 18 & Sibada & United Kingdom (NE) & Cultivar & 65 & $02-105$ & Dazhou, Sichuan, China (SC) & Wild \\
\hline 19 & Cristobal & France (WE) & Cultivar & 66 & $02-106$ & Baoxing, Sichuan, China (SC) & Wild \\
\hline 20 & Bote & Italy (WE) & Cultivar & 67 & $02-107$ & Baoxing, Sichuan, China (SC) & Wild \\
\hline 21 & Asuosi & Luxembourg (WE) & Cultivar & 68 & $02-108$ & Baoxing, Sichuan, China (SC) & Wild \\
\hline 22 & PI384017 & Netherlands (WE) & Cultivar & 69 & $02-109$ & Baoxing, Sichuan, China (SC) & Wild \\
\hline 23 & 00737 & Netherlands (WE) & Wild & 70 & $90-130$ & Maoxian, Sichuan, China (SC) & Wild \\
\hline 24 & $79-118$ & Netherlands (WE) & Wild & 71 & $90-70$ & Kangding, Sichuan, China (SC) & Wild \\
\hline 25 & PI311033 & Romania (WE) & Cultivar & 72 & $91-1$ & Hanyuan, Sichuan, China (SC) & Wild \\
\hline 26 & Kaimo & Spain (WE) & Cultivar & 73 & $91-103$ & Yuexi, Sichuan, China (SC) & Wild \\
\hline 27 & Intensiv & Czech (CE) & Cultivar & 74 & Baoxing & Baoxing, Sichuan, China (SC) & Cultivar \\
\hline 28 & 96011 & Germany (CE) & Wild & 75 & Chuandong & Daxian, Sichuan, China (SC) & Cultivar \\
\hline 29 & PI260244 & Bavaria, Germany (CE) & Cultivar & 76 & Gulin & Gulin, Sichuan, China (SC) & Cultivar \\
\hline 30 & Denata & Germany $(\mathrm{CE})$ & Cultivar & 77 & Yangping & Hongya, Sichuan, China (SC) & Wild \\
\hline 31 & Jinniu & Germany (CE) & Cultivar & 78 & $02-110$ & Yunnan, China (SC) & Wild \\
\hline 32 & PI288998 & Hungary (CE) & Cultivar & 79 & $02-111$ & Yunnan, China (SC) & Wild \\
\hline 33 & PI273738 & Lithuania (CE) & Cultivar & 80 & $02-112$ & Yunnan, China (SC) & Wild \\
\hline 34 & PI305498 & Poland (CE) & Cultivar & 81 & $02-113$ & Yunnan, China (SC) & Wild \\
\hline 35 & Dana & Slovakia (CE) & Cultivar & 82 & $02-114$ & Qujing, Yunnan, China (SC) & Wild \\
\hline 36 & 02681 & Canada (NA) & Wild & 83 & $02-115$ & Yunnan, China (SC) & Wild \\
\hline 37 & PI278699 & Canada (NA) & Cultivar & 84 & $02-116$ & Kunming, Yunnan, China (SC) & Cultivar \\
\hline 38 & 00595 & United States (NA) & Wild & 85 & 00947 & Hubei, China (NC) & Wild \\
\hline 39 & 00937 & United States (NA) & Wild & 86 & 02122 & Hubei, China (NC) & Wild \\
\hline 40 & 01076 & United States (NA) & Wild & 87 & Tieluoping & Hubei, China (NC) & Wild \\
\hline 41 & 01436 & United States (NA) & Wild & 88 & 02746 & Gansu, China (NC) & Wild \\
\hline 42 & 01476 & United States (NA) & Wild & 89 & 01032 & Xinjiang, China (NC) & Wild \\
\hline 43 & 01821 & United States (NA) & Wild & 90 & 02068 & Xinjiang, China (NC) & Wild \\
\hline 44 & 98-101 & United States (NA) & Wild & 91 & 02105 & Xinjiang, China (NC) & Wild \\
\hline 45 & $98-102$ & Oregon, United States (NA) & Wild & 92 & 02106 & Xinjiang, China (NC) & Wild \\
\hline 46 & PI578668 & Iowa, United States (NA) & Cultivar & 93 & 02138 & Xinjiang, China (NC) & Wild \\
\hline \multirow[t]{2}{*}{47} & Yuanhang & United States (NA) & Cultivar & 94 & 02240 & Xinjiang, China (NC) & Wild \\
\hline & & & & 95 & 02271 & Xinjiang, China (NC) & Wild \\
\hline
\end{tabular}

$\mathrm{NE}=$ northern Europe; $\mathrm{WE}=$ western Europe; $\mathrm{CE}=$ central Europe; $\mathrm{NA}=$ North America; $\mathrm{OC}=$ Oceania; $\mathrm{SC}=$ southern China, and $\mathrm{NC}=$ northern China.

\section{SCoT polymerase chain reaction (PCR) amplification}

All SCoT primers were synthesized by the Shanghai Sangon Biological Engineering Technology \& Services (China). Eighty primers were initially screened for polymorphism and reproducibility using 4 accessions, i.e., 01-101, 2006-5, Anba, and Baoxing. Each 15- $\mu \mathrm{L}$ amplification reaction consisted of $10 \mathrm{ng}$ template DNA, 7.5 $\mu \mathrm{L} 2 \mathrm{X}$ Reaction Mix (Tiangen ${ }^{\circledR}$, China), $0.4 \mu \mathrm{L} 2.5 \mathrm{U} / \mu \mathrm{L}$ Golden DNA Polymerase (Tiangen ${ }^{\circledR}$, China), $1.5 \mu \mathrm{L} 10 \mu \mathrm{M}$ primer, and 4.6 $\mu \mathrm{L}$ distilled water. PCR amplification was performed on a Peltier Thermal Cycler (DNA En- 
gine ${ }^{\circledR}$, Bio-Rad, USA) using the following program: $94^{\circ} \mathrm{C}$ for $3 \mathrm{~min} ; 36$ cycles of $94^{\circ} \mathrm{C}$ for 50 $\mathrm{s}, 50^{\circ} \mathrm{C}$ for $1 \mathrm{~min}$, and $72^{\circ} \mathrm{C}$ for $2 \mathrm{~min}$; a final extension at $72^{\circ} \mathrm{C}$ for $5 \mathrm{~min}$; and a $4^{\circ} \mathrm{C}$ holding temperature. Amplified fragments were resolved on 1.8\% agarose gels in $1 \mathrm{X}$ Tris-acetate-ethylenediaminetetraacetic acid buffer and stained with GelRed ${ }^{\mathrm{TM}}(10,000 \mathrm{X}$ in water). The banding pattern images were acquired under UV light using the Gel Doc XR system (Bio-Rad, USA).

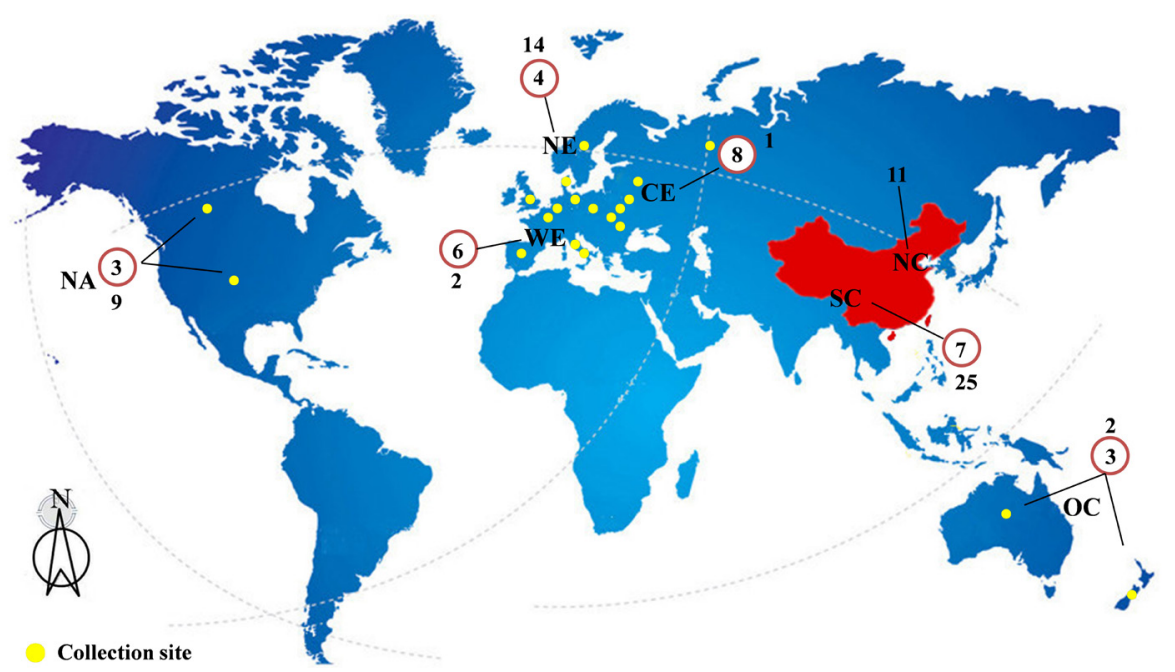

Figure 1. Geographic map showing the location of 95 accessions of Dactylis glomerata from 21 countries and 7 geographical regions (NE, WE, CE, NA, OC, SC, NC). Numbers of cultivated or cultivar analyzed are shown within circles, and numbers of wild are shown outside of the circles, the yellow polka dot represent the collection site of $D$. glomerata. For abbreviations, see legend to Table 1.

\section{Statistical analysis}

The polymorphic information content $(P I C)$ of each SCoT marker analyzed was calculated using the formula: $P I C=1-\sum P_{i j}^{2}$, where $P_{i j}$ was the frequency of the $j$ th allele for the $i$ th locus, summed across all alleles of the locus (Nei, 1973). Reproducible bands were scored as absent (0) or present (1) for each of the SCoT markers. The POPGENE software version 1.31 (Yeh et al., 1999) was used to estimate the genetic diversity parameters grouped, percentage polymorphic loci $(P P L)$, Nei's (Nei, 1973) gene diversity $(H)$, Shannon's information index of diversity $(I)$, and number of polymorphic loci $(N P L)$ from the 1/0 matrices generated. Nei's unbiased measures of genetic identity $(G I)$ and genetic distance $(G D)$ among 7 geographical regions were also calculated using the same program (Nei, 1978). Cluster analysis based on the GD matrix among geographical regions was constructed using the NTSYS version 2.10 software (Rohlf, 2000). Analysis of molecular variance (AMOVA) was used to partition the total SCoT marker variation into the within and among geographical regions components (Excoffier et al., 1992). The input files for AMOVA were prepared by the DCFA1.1 program (Zhang, 2001). Nei and Li's (Nei and Li, 1979) pairwise similarities between 95 accessions were computed by the FreeTree program (Pavlícek et al., 1999), and a bootstrap analysis with 10,000 replicates was performed. A dendrogram showing the genetic relationships among accessions based on the unweighted pair-group method with arithmetic averages (UPGMA) was constructed using the Dendroscope 3 program (Huson and Scornavacca, 2012). 


\section{RESULTS}

\section{SCoT polymorphism and genetic diversity}

The results of 24 primers that were used to screen SCoT markers of 95 orchardgrass accessions are summarized in Table 2. The SCoT primers were screened according to the methods described by Collard and Mackill (2009) and Luo et al. (2010). In prescreening assays with 4 orchardgrass accessions and 80 SCoT primers, clear reproducible polymorphic amplification products were generated by 24 primers, which were selected for genetic relationship analysis of orchardgrass in this study. Among the 95 orchardgrass accessions, 324 reliable bands were obtained from 24 SCoT primers. The total number of bands (TNB) per primer ranged from 6 to 19 the average $T N B$ per primer was 13.5. The maximum TNB (19) was found for primers SCoT40 and SCoT61, whereas the lowest TNB (6) was obtained for SCoT10. Among the total obtained fragments, 273 bands were polymorphic with the average of $83.4 \%$ polymorphism, and the detected polymorphism per primer among the tested accessions ranged from 50\% (SCoT11) to 100\% (SCoT7, SCoT45, SCoT54, SCoT59, SCoT60, and SCoT65). The number of polymorphic bands $(N P B)$ varied from 5 (SCoT10 and SCoT11) to 18 (SCoT65) with an average $N P B$ of 11.4 per primer.

\section{Table 2. Amplification results of Dactylis glomerata from 24 start codon-targeted (SCoT) primers.}

\begin{tabular}{|c|c|c|c|c|c|c|}
\hline Primer ID & Primer Sequence $\left(5^{\prime}-3^{\prime}\right)$ & $\% \mathrm{G} / \mathrm{C}$ & TNB & NPB & $P(\%)$ & $P I C$ \\
\hline 6 & CAACAATGGCTACCACGC & 56 & 10 & 6 & 60.00 & 0.8973 \\
\hline 7 & CAACAATGGCTACCACGG & 56 & 7 & 7 & 100.00 & 0.8276 \\
\hline 8 & CAACAATGGCTACCACGT & 50 & 9 & 8 & 88.89 & 0.8796 \\
\hline 9 & CAACAATGGCTACCAGCA & 50 & 9 & 8 & 88.89 & 0.8703 \\
\hline 10 & CAACAATGGCTACCAGCC & 56 & 6 & 5 & 83.33 & 0.8307 \\
\hline 11 & AAGCAATGGCTACCACCA & 50 & 10 & 5 & 50.00 & 0.8773 \\
\hline 12 & ACGACATGGCGACCAACG & 61 & 10 & 6 & 60.00 & 0.8970 \\
\hline 20 & ACCATGGCTACCACCGCG & 67 & 9 & 6 & 66.67 & 0.8621 \\
\hline 23 & CACCATGGCTACCACCAG & 61 & 17 & 12 & 70.59 & 0.9325 \\
\hline 26 & ACCATGGCTACCACCGTC & 61 & 18 & 16 & 88.89 & 0.9384 \\
\hline 28 & CCATGGCTACCACCGCCA & 67 & 14 & 12 & 85.71 & 0.8777 \\
\hline 29 & CCATGGCTACCACCGGCC & 72 & 17 & 11 & 64.71 & 0.9292 \\
\hline 30 & CCATGGCTACCACCGGCG & 72 & 15 & 13 & 86.67 & 0.9170 \\
\hline 36 & GCAACAATGGCTACCACC & 56 & 11 & 9 & 81.82 & 0.8964 \\
\hline 40 & CAATGGCTACCACTACAG & 50 & 19 & 17 & 89.47 & 0.9402 \\
\hline 44 & CAATGGCTACCATTAGCC & 50 & 16 & 12 & 75.00 & 0.9234 \\
\hline 45 & ACAATGGCTACCACTGAC & 50 & 17 & 17 & 100.00 & 0.9313 \\
\hline 54 & ACAATGGCTACCACCAGC & 56 & 14 & 14 & 100.00 & 0.9129 \\
\hline 59 & ACAATGGCTACCACCATC & 50 & 15 & 15 & 100.00 & 0.9264 \\
\hline 60 & ACAATGGCTACCACCACA & 50 & 14 & 14 & 100.00 & 0.9241 \\
\hline 61 & CAACAATGGCTACCACCG & 56 & 19 & 14 & 73.68 & 0.9378 \\
\hline 62 & ACCATGGCTACCACGGAG & 61 & 16 & 15 & 93.75 & 0.9247 \\
\hline 63 & ACCATGGCTACCACGGGC & 67 & 14 & 13 & 92.86 & 0.9127 \\
\hline 65 & ACCATGGCTACCACGGCA & 61 & 18 & 18 & 100.00 & 0.9362 \\
\hline Average & & & 13.5 & 11.4 & 83.37 & 0.9043 \\
\hline Total & & & 324 & 273 & 84.26 & \\
\hline
\end{tabular}

$\mathrm{TNB}=$ total number of bands; $\mathrm{NPB}=$ number of polymorphic bands; $P=$ polymorphic rate $P I C=$ polymorphic information content.

PIC varied from 0.8276 for SCoT7 to 0.9402 for SCoT40. The average value was 0.9043 for this species (Table 2). In order to obtain a detailed view of the genetic variation within different geographical regions, $H, I, N P L$, and $P P L$ were estimated. The 4 genetic 
diversity parameters for all accessions were $0.27,0.41,273$, and $84.26 \%$, respectively. The high values of the 4 genetic diversity parameters $(N P L=213 ; H=0.2627 ; I=0.3826 ; P P L=$ $65.74 \%)$ were found from $\mathrm{WE}$, and the maximum values $(N P L=251 ; H=0.2935 ; I=0.4320$; $P P L=77.47 \%$ ) for orchardgrass were from Europe; the values were followed by values for orchardgrass from China $(N P L=213 ; H=0.2376 ; I=0.3530 ; P P L=65.74 \%)$, and the lowest values $(N P L=116 ; H=0.1297 ; I=0.1931 ; P P L=35.80 \%)$ were for orchardgrass from OC. Among the 7 geographical regions, the $P P L$ ranged from $35.80 \%$ (OC) to $65.74 \%$ (WE) in the following order: $\mathrm{WE}>\mathrm{SC}>\mathrm{NC}>\mathrm{NE}>\mathrm{CE}>\mathrm{NA}>\mathrm{OC}$ (Table 3).

\begin{tabular}{|c|c|c|c|c|c|}
\hline Groups & $\mathrm{N}$ & $N P L$ & $H$ & I & $P P L(\%)$ \\
\hline Europe & 35 & 251 & 0.2935 & 0.4320 & 77.47 \\
\hline Northern Europe (NE) & 18 & 151 & 0.1623 & 0.2418 & 46.60 \\
\hline Western Europe (WE) & 8 & 213 & 0.2627 & 0.3826 & 65.74 \\
\hline Central Europe (CE) & 9 & 135 & 0.1504 & 0.2234 & 41.67 \\
\hline China & 43 & 213 & 0.2376 & 0.3530 & 65.74 \\
\hline Northern China (NC) & 32 & 176 & 0.1975 & 0.2932 & 54.32 \\
\hline Southern China (SC) & 11 & 192 & 0.2174 & 0.3224 & 59.26 \\
\hline North America (NA) & 12 & 117 & 0.1311 & 0.1941 & 36.11 \\
\hline Oceania (OC) & 5 & 116 & 0.1297 & 0.1931 & 35.80 \\
\hline Total & 95 & 273 & 0.2664 & 0.4050 & 84.26 \\
\hline
\end{tabular}

$\mathrm{N}=$ number of accessions; $N P L=$ number of polymorphic loci; $H=$ Nei's gene diversity; $I=$ Shannon's information index of diversity; $P P L=$ percentage of polymorphic loci.

\section{Cluster analysis}

All of the 324 scored bands were used to calculate the genetic similarity $(G S)$ among the 95 orchardgrass accessions. The $G S$ ranged from 0.514 to 0.949 with an average of 0.715 . The highest GS observed (0.949) was found between 00937 (United States) and 01821 (United States), whereas the lowest $G S(0.514)$ was obtained between 01032 (China) and Dana (Europe). The GDs among the 7 geographical groups were estimated by Nei's (Nei, 1978) unbiased measure (Table 4). The GDs among the 7 geographical groups varied from 0.052 (NA and OC) to 0.3423 (CE and SC) with an average of 0.1554 (Table 4). The UPGMA dendrogram based on $G D$ showed that group NA has the largest genetic distance with $\mathrm{OC}$, and materials from the geographical regions of China (NC and SC) showed high genetic similarity and were grouped together (Figure 2).

\section{Table 4. Nei's unbiased measures of genetic distance for Dactylis glomerata.}

\begin{tabular}{lcccccr}
\hline Groups & NE & WE & CE & NC & SC & NA \\
\hline NE & 0.0000 & & & & & \\
WE & 0.0871 & 0.0000 & & & & \\
CE & 0.2861 & 0.2585 & 0.0000 & & & \\
NC & 0.0608 & 0.1312 & 0.2516 & 0.0000 & & \\
SC & 0.1160 & 0.1216 & $\underline{0.3423}$ & 0.1504 & 0.0000 & 0.0000 \\
NA & 0.0775 & 0.0795 & 0.3041 & 0.1053 & 0.0858 & 0.0520 \\
OC & 0.0923 & 0.0777 & 0.3412 & 0.1425 & 0.0995 & 0.0000 \\
\hline
\end{tabular}

Underlined values represent the maximums and minimums of genetic distance values. 


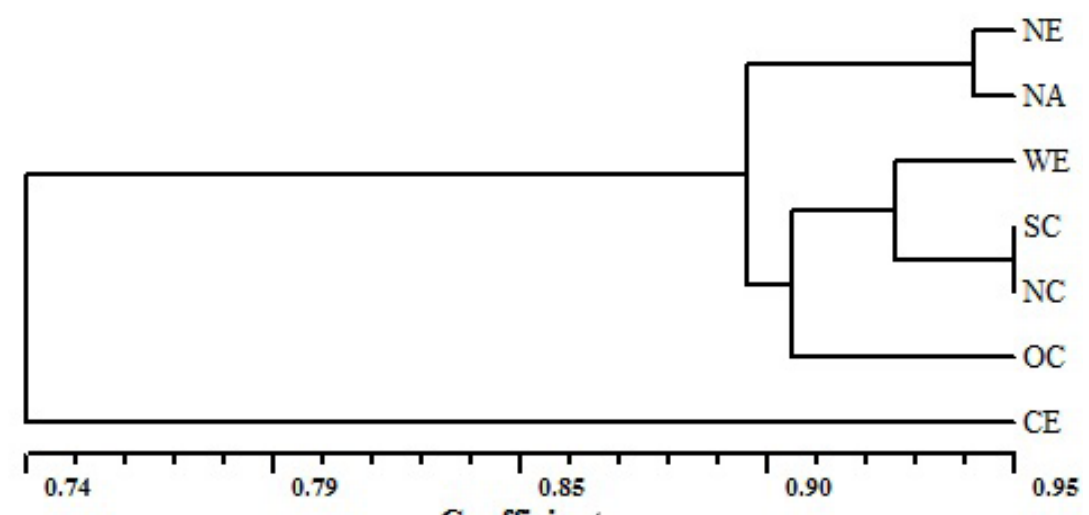

Figure 2. Cluster tree between the seven geographical regions of Dactylis glomerata based on Nei's (1973) genetic identity.

A dendrogram was obtained by UPGMA using the total number of amplified SCoT fragments and revealed the genetic relationships of the 95 accessions (Figure 3), which were grouped into 7 main clusters. The accessions were clustered mainly according to the geographic origin.

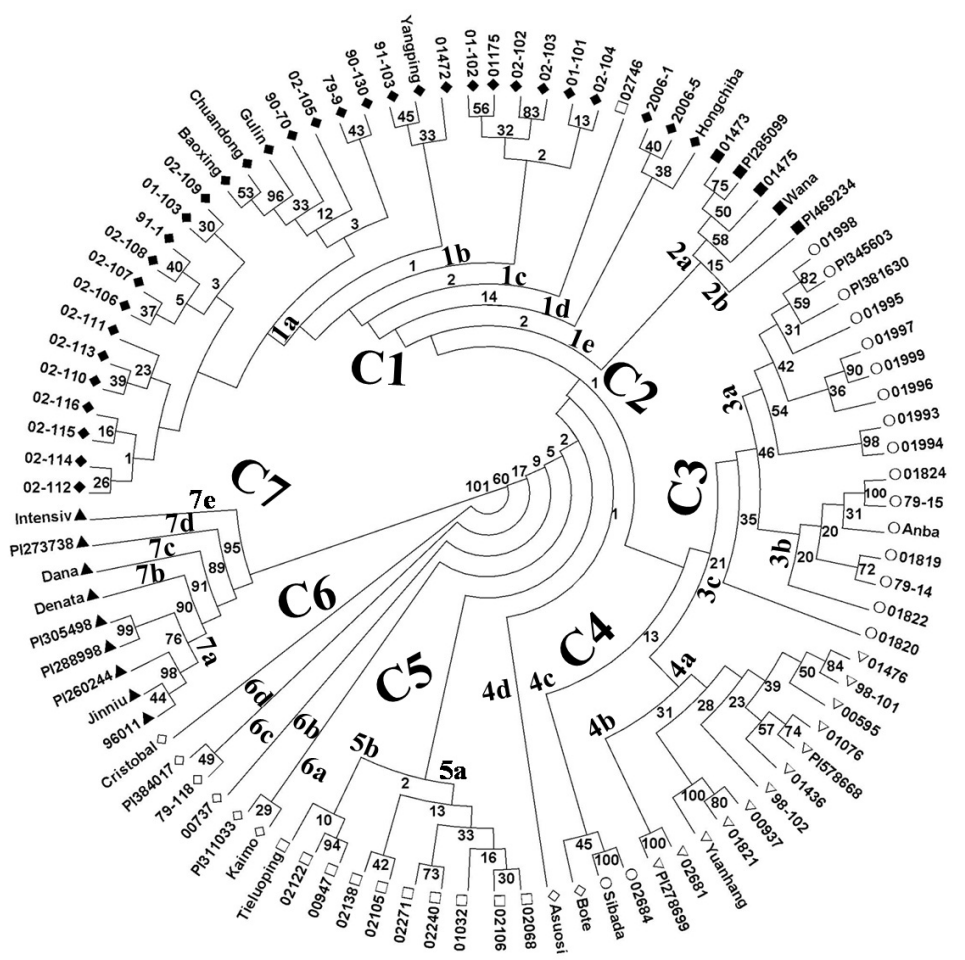

Figure 3. Dendrograms generated using UPGMA analysis, showing relationships between different Dactylis glomerata accessions using SCoT markers. Open square $=$ northern China; filled diamond $=$ southern China; open diamond = western Europe; open circle = northern Europe; filled triangle = central Europe; open triangle $=$ North America; filled square $=$ Oceania . 
Cluster $1(\mathrm{C} 1)$ included 33 accessions and could be further divided into 5 subgroups. Subgroup 1 (1a) was very large; the accessions from Yunnan (02-110, 02-111, 02-112, 02-113, 02-114, 02-115, and 02-116), Sichuan (02-105, 02-106, 02-107, 02-108, 02-109, 91-1, 01-103, 90-70, 90-130, Baoxing, Chuandong, and Gulin) and Jiangxi (79-9) formed one branch of subgroup 1. The accessions from Guizhou (01175, 01-101, 01-102, 02-102, 02-103, and 02-104) were in subgroup 3 (1c); subgroup 5 (1e) included accessions from Chongqing (2006-1, 2006-5, and Hongchiba); and subgroup 2 (1b) included accessions 91103 and Yangping from Sichuan and 01472 from Chongqing. All of the accessions belonging to the SC geographical region except 02746 , which belongs to the $\mathrm{NC}$ region, were grouped into subgroup 4 (1d). Cluster 2 (C2) divided all of the accessions from the OC region into subgroup 1 (2a) (01473, 01475, PI285099, and Wana) and subgroup 2 (2b) (PI469234). Cluster 3 (C3) included 16 accessions and 3 subgroups from the NE region. Subgroup 1 (3a) included accessions from Russia (PI345603) and Sweden (PI381630, 01993, 01994, 01995, 01996, 01997, 01998, and 01999). Accessions 01819, 01822, 01824, 79-14, 79-15, and Anba from Denmark were grouped into subgroup 2 (3b), and accession 01820 from Denmark was placed in subgroup 3 (3c). Cluster 4 (C4) included 16 accessions and could be further divided into 4 subgroups. The accessions from the United States (00595, 00937, 01076, 01436, 01476, 01821, 98-101, 98-102, PI578668, and Yuanhang) and Canada (02681 and PI278699) belong to the NA region and were placed in subgroup 1 (4a) and subgroup 2 (4b), respectively. Subgroup 3 (4c) included Sibada and 02681 from the NE region and Bote from the WE region. Asuosi (WE) was in subgroup 4 (4d). The accessions from the $\mathrm{NC}$ region were grouped in cluster 5 (C5), which was divided into subgroup 1 (5a) $(00947,02122$, and Tieluoping from Hubei) and subgroup 2 (5b) (02746, 01032, 02068, 02105, 02106, 02138, 02240, and 02271 from Xinjiang). The accessions from the WE region (Cristobal, PI384017, 00737, 79-118, PI311033, and Kaimo) were grouped in cluster 6 (C6) and further divided into 4 subgroups. Cluster 7 (C7) included 9 accessions from the CE region (Intensiv, 96011, PI260244, Denata, Jinniu, PI288998, PI273738, PI305498, and Dana) and could be further divided into 5 subgroups (Figure 3).

\section{AMOVA}

AMOVA of the 5 orchardgrass groups revealed that 83.02 and $16.98 \%$ of the variation resided within and among groups (Europe, China, Oceania, and North America), respectively. AMOVA also revealed that 30.87 and $69.13 \%$ of the variation resided within and among the 7 regions (NE, WE, CE, NA, OC, SC, and NC), respectively (Table 5).

Table 5. Analysis of molecular variance (AMOVA) distribution for Dactylis glomerata in this study.

\begin{tabular}{lcccc}
\hline Source of variation & Sum of squares & Variance component & Percentage of variation & P values \\
\hline Analysis among populations & & & & \\
Among population & 1133.33 & 12.64 & $30.87 \%$ & $<0.001$ \\
Within populations & 2490.58 & 28.30 & $69.13 \%$ & $<0.001$ \\
Analysis among groups & & & & $<0.001$ \\
Among groups & 525.82 & 6.96 & $83.02 \%$ & $<0.001$ \\
Within groups & 3098.10 & 34.05 & $83.02 \%$ \\
\hline
\end{tabular}




\section{DISCUSSION}

\section{SCoT polymorphism of orchardgrass}

The use of isozymes technology is limited for agronomic trait evaluation, which could be affected by the growing environment and restricts their use for assessing genetic diversity (Xie et al., 2010). In contrast, molecular markers can provide abundant information and are not limited by the environment, which makes them better tools to characterize the genetic diversity among accessions. SCoT markers are designed from the short conserved region flanking the ATG start codon of all plant genes (Collard and Mackill, 2009). Previously, more than 80 primers were released for SCoT analysis (Collard and Mackill, 2009; Luo et al., 2010). Compared with other molecular markers, SCoT markers have emerged as an alternative system with several advantages: lower cost than AFLP, higher reproducibility than RAPD, and easier development of species-specific primers than SSR (Guo et al., 2012). Luo et al. (2010) showed that amplification products generated from the SCoT marker technique were associated with functional genes and their corresponding traits. Xiong et al. (2011) showed that SCoT markers could be utilized to identify DNA polymorphisms and fingerprint cultivars in domesticated peanut. Gorji et al. (2011) reported that SCoT markers were more informative for fingerprinting varieties than other markers based on the average percentage of polymorphism, $P I C$, and overall $I$. Therefore, SCoT markers have been extensively used in plants to characterize $G D$ in a wide range of species (Collard and Mackill, 2009; Xiong et al., 2009, 2010, 2011; Luo et al., 2010; Gorji et al., 2011; Guo et al., 2012). As far as we know, this is the first GD analysis of orchardgrass using SCoT markers.

In this study, 24 SCoT primers were used to estimate the $G D$ of orchardgrass accessions. Primers that produced only a few or many fragments were rejected, and those with poor reproducibility in repetitive experiments were not scored. Of the 324 scored fragments, 273 bands were polymorphic. The bands from 6 SCoT primers were $100 \%$ polymorphic, and the average polymorphic value was $83.4 \%$. This value was lower than that reported by Guo et al. (2012) $(\mathrm{P}=93.1 \%)$ in 64 grape varieties, but it was higher than that reported by Luo et al. (2010) $(\mathrm{P}=76.19 \%)$ in mango accessions. The average $T N B$ and $N P B$ was 13.5 and 11.4 , respectively, indicating the high discriminating ability of the SCoT technique for orchardgrass. The $P I C$ values ranged from 0.8276 to 0.9402 with an average of 0.9043 , indicating that these loci were highly informative. The PIC value is higher than those reported by Xie et al. [2010 $(\mathrm{PIC}=0.77), 2012(\mathrm{PIC}=0.81)]$ in orchardgrass, which indicated that SCoT markers could contribute substantial information to the genetics and breeding research of orchardgrass.

Among the 7 geographic regions, the genetic variation of orchardgrass from WE (P $=65.74 \%), \mathrm{SC}(\mathrm{P}=59.26 \%)$, and $\mathrm{NC}(\mathrm{P}=54.32 \%)$ were higher than the values from other regions, i.e., $\mathrm{NE}(\mathrm{P}=46.60 \%), \mathrm{CE}(\mathrm{P}=41.67 \%)$, $\mathrm{NA}(\mathrm{P}=36.11 \%)$, and $\mathrm{OC}(\mathrm{P}=35.80 \%)$. These results might be influenced by the number of samples and the complicated natural conditions of the geographic regions, and they indicated that orchardgrass from Europe and China might provide high $G D$ for breeding and germplasm collection. In addition, the cluster analysis of the geographical groups showed a similarity between the groups from the same regions: the accessions from China (SC and NC) had a low distance and the best affinity relationship (Table 4). Differences in the climates and breeding systems might lead to differences in the genetic constitution of orchardgrass. In general, our results also agreed with previous research performed by Xie et al. (2010). 


\section{Cluster analysis}

In this study, the $G S$ values ranged from 0.514 to 0.949 with an average of 0.715 between 95 accessions, which was higher than the value that was reported by Bushman et al. (2011) $(G S=0.44-0.70)$. This confirmed a high level of genetic diversity among orchardgrass. The dendrogram obtained using UPGMA consisted of 7 major clusters (Figure 3), which were mainly separated according to the geographical origin. Each cluster was further divided into subgroups. However, a few accessions were not clustered into the group that included other accessions from its geographical region. For example, 02746 from Gansu, China, was from the NC region (C5) but was clustered with accessions from the SC region (C1), 02684 and Sibada from the United Kingdom belonged to the NE region (C3) but were clustered with the NA region (C4), Bote and Asuosi belonged to the WE region (C4) but were also clustered with the NA region (C4) (Figure 3). This clustering might be influenced by the allogamous characteristic of orchardgrass and the breeding system and gene flow among different geographical regions with variations in the culture, bird migration, and breeder selection.

\section{Genetic variation based on SCoT markers}

AMOVA for accessions is very important and contributes to the comprehensive understanding of germplasms and breeding (Excoffier et al., 1992). Large variation mainly existed within geographical groups; this variation pattern is in accordance with an ecotype study in fescue (Kölliker et al., 1999). We successfully used AMOVA to examine the distribution of variance within and among groups (Europe, China, Oceania, and North America) and regions (NE, WE, CE, NA, OC, SC, and NC). Both results (83.02 and 69.13\%) indicated a large variation within geographical groups, which was consistent with results by Xie et al. (2010), who revealed $74.87 \%$ genetic variation within geographical regions using SSR markers. Additionally, Peng et al. (2008) used AFLP markers and detected 85.65\% variation within geographical regions. The results demonstrated that the orchardgrass germplasms had a high level of $G D$ within geographical regions than among geographical regions, which might play a guiding role in the management and breeding of orchardgrass.

\section{Conservation implications}

A study of the distribution and genetic variation of a species revealed the preconditions that are necessary to establish and implement effective and economical protection measures (Hamrick and Godt, 1996). It is important to recognize the $G D$ and variation among and within accessions to choose the relevant strategy for the protection and understanding of orchardgrass, which has a great impact on the development of animal husbandry and agricultural practices. This research demonstrated that SCoT markers could present high GD and geographical differentiation for D. glomerata, which provided potency for further genetic analysis, germplasm collection, and conservation. D. glomerata is a perennial allogamous forage grass species. Effective measures to avoid natural pollination would contribute to the conservation and understanding of orchardgrass. In addition, more attention should be paid to the collection and preservation of orchardgrass germplasms worldwide from different ecogeographical regions, climatic types, and mountain ranges. 
In conclusion, the results of this study suggested that the SCoT markers were a highly reproducible, efficient, and powerful tool to assess genetic relationships among orchardgrass accessions. This analysis revealed that $D$. glomerata had abundant $G D$ and high variability within geographical regions.

\section{ACKNOWLEDGMENTS}

Research supported by the Earmarked Fund for Modern Agro-Industry Technology Research System (\#CARS-35-05), the National Natural Science Foundation of China (\#31372363), the National Basic Research Program ("973" Program) of China (\#2014CB138705), and the Research Fund for the Doctoral Program of Higher Education of China (\#20115103120004).

\section{REFERENCES}

Andersen JR and Lübberstedt T (2003). Functional markers in plants. Trends Plant Sci. 8: 554-560.

Bolaric S, Barth S, Melchinger AE and Posselt UK (2005). Genetic diversity in European perennial ryegrass cultivars investigated with RAPD markers. Plant Breed. 124: 161-166.

Bushman BS, Larson SR, Tuna M, West MS, et al. (2011). Orchardgrass (Dactylis glomerata L.) EST and SSR marker development, annotation, and transferability. Theor. Appl. Genet. 123: 119-129.

Collard BCY and Mackill DJ (2009). Start codon targeted (SCoT) polymorphism: a simple, novel DNA marker technique for generating gene-targeted markers in plants. Plant Mol. Biol. Rep. 27: 86-93.

Degani C, Deng J, Beiles A and El-Batsri R (2003). Identifying lychee (Litchi chinensis Sonn.) cultivars and their genetic relationships using intersimple sequence repeat (ISSR) markers. J. Am. Soc. Hortic. Sci. 128: 838-845.

Excoffier L, Smouse PE and Quattro JM (1992). Analysis of molecular variance inferred from metric distances among DNA haplotypes: application to human mitochondrial DNA restriction data. Genetics 131: 479-491.

Gauthier P, Lumaret R and Bédécarrats A (1998). Ecotype differentiation and coexistence of two parapatric tetraploid subspecies of cocksfoot (Dactylis glomerata) in the Alps. New Phytol. 139: 741-750.

Gorji AM, Poczai P, Polgar Z and Taller J (2011). Efficiency of arbitrarily amplified dominant markers (SCOT, ISSR and RAPD) for diagnostic fingerprinting in tetraploid potato. Am. J. Potato Res. 88: 226-237.

Guo DL, Zhang JY and Liu CH (2012). Genetic diversity in some grape varieties revealed by SCoT analyses. Mol. Biol. Rep. 39: 5307-5313.

Hamrick JL and Godt MJW (1996). Conservation Genetics of Endemic Plant Species. In: Conservation Genetics, Case Histories from Nature (Avise JC and Hamrick JL, eds.). Chapman and Hall, New York, 281-304.

Hirata M, Yuyama N and Cai HW (2011). Isolation and characterization of simple sequence repeat markers for the tetraploid forage grass Dactylis glomerata. Plant Breed. 130: 503-506.

Huson DH and Scornavacca C (2012). Dendroscope 3: an interactive tool for rooted phylogenetic trees and networks. Syst. Biol. 61: 1061-1067.

Jafari A and Naseri H (2007). Genetic variation and correlation among yield and quality traits in cocksfoot (Dactylis glomerata L.). J. Agr. Sci. 610.

Kölliker R, Stadelmann FJ, Reidy B and Nösberger J (1999). Genetic variability of forage grass cultivars: a comparison of Festuca pratensis Huds., Lolium perenne L., and Dactylis glomerata L. Euphytica 106: 261-270.

Lindner R and Garcia A (1997). Geographic distribution and genetic resources of Dactylis in Galicia (northwest Spain). Genet. Resour. Crop Ev. 44: 499-507.

Liu CJ (1997). Geographical distribution of genetic variation in Stylosanthes scabra revealed by RAPD analysis. Euphytica 98: 21-27.

Luo C, He XH, Chen H, Ou SJ, et al. (2010). Analysis of diversity and relationships among mango cultivars using start codon targeted (SCoT) markers. Biochem. Syst. Ecol. 38: 1176-1184.

Nei M (1973). Analysis of gene diversity in subdivided populations. Proc. Natl. Acad. Sci. U. S. A. 70: 3321-3323.

Nei M (1978). Estimation of average heterozygosity and genetic distance from a small number of individuals. Genetics 89: 583-590.

Nei M and Li WH (1979). Mathematical model for studying genetic variation in terms of restriction endonucleases. Proc. 
Natl. Acad. Sci. U. S. A. 76: 5269-5273.

Pavlícek A, Hrda S and Flegr J (1999). Free-Tree-freeware program for construction of phylogenetic trees on the basis of distance data and bootstrap/jackknife analysis of the tree robustness. Application in the RAPD analysis of genus Frenkelia. Folia Biol. 45: 97-99.

Peng Y, Zhang XQ, Deng YL and Ma X (2008). Evaluation of genetic diversity in wild orchardgrass (Dactylis glomerata L.) based on AFLP markers. Hereditas 145: 174-181.

Reeves G, Francis D, Davies MS and Rogers HJ (1998). Genome size is negatively correlated with altitude in natural populations of Dactylis glomerata L. Ann. Bot. 82: 99-105.

Rohlf FJ (2000). NTSYS-pc: Numerical Taxonomy and Multivariate Analysis System. Version 2.1. User Guide. Exeter Software, Setauket.

Roldán-Ruiz I, van Eeuwijk FA, Gilliland TJ, Dubreuil P, et al. (2001). A comparative study of molecular and morphological methods of describing relationships between perennial ryegrass (Lolium perenne L.) varieties. Theor. Appl. Genet. 103: 1138-1150.

Sanada Y, Takai T and Yamada T (2007). Ecotypic variation of water-soluble carbohydrate concentration and winter hardiness in cocksfoot (Dactylis glomerata L.). Euphytica 153: 267-280.

Sanada Y, Tamura K and Yamada T (2010). Relationship between water-soluble carbohydrates in fall and spring and vigor of spring regrowth in orchardgrass. Crop Sci. 50: 380-390.

Semagn K, Bjørnstad A and Ndjiondjop M (2006). An overview of molecular marker methods for plants. Afr. J. Biotechnol. 5: $2540-2568$.

Stewart AV and Ellison NW (2011). Dactylis. In: Wild Crop Relatives: Genomic and Breeding Resources, Millets and Grasses (Kole C, ed.). Springer, New York, 73-78.

Tuna M, Khadka DK, Shrestha MK and Arumuganathan K (2004). Characterization of natural orchardgrass (Dactylis glomerata L.) populations of the Thrace Region of Turkey based on ploidy and DNA polymorphisms. Euphytica 135: 39-46.

Xie WG, Zhang XQ, Cai HW, Liu W, et al. (2010). Genetic diversity analysis and transferability of cereal EST-SSR markers to orchardgrass (Dactylis glomerata L.). Biochem. Syst. Ecol. 38: 740-749.

Xie W, Zhang X, Cai H, Huang L, et al. (2011). Genetic maps of SSR and SRAP markers in diploid orchardgrass (Dactylis glomerata L.) using the pseudo-testcross strategy. Genome 54: 212-221.

Xie WG, Lu XF, Zhang XQ, Huang LK, et al. (2012). Genetic variation and comparison of orchardgrass (Dactylis glomerata L.) cultivars and wild accessions as revealed by SSR markers. Genet. Mol. Res. 11: 425-433.

Xiong FQ, Tang RH, Chen ZL and Pan LH (2009). SCoT: a novel gene targeted marker technique based on the translation start codon. Mol. Plant Breed. 7: 635-638.

Xiong FQ, Jiang J, Zhong RC, Han ZQ, et al. (2010). Application of SCoT molecular marker in genus Arachis. Acta Agron. Sin. 36: 2055-2061.

Xiong F, Zhong R, Han Z, Jiang J, et al. (2011). Start codon targeted polymorphism for evaluation of functional genetic variation and relationships in cultivated peanut (Arachis hypogaea L.) genotypes. Mol. Biol. Rep. 38: 3487-3494.

Yeh FC, Yang RC and Boyle T (1999). POPGENE VERSION 1.31. Microsoft Windows-Based Freeware for Population Genetic Analysis. Quick user guide. University of Alberta: Center for International Forestry Research, Edmonton.

Zeng B, Zhang XQ, Lan Y and Yang WY (2008). Evaluation of genetic diversity and relationships in orchardgrass (Dactylis glomerata L.) germplasm based on SRAP markers. Can. J. Plant Sci. 88: 53-60.

Zeng B, Zhang XQ, Fan Y, Lan Y, et al. (2006). Genetic diversity of Dactylis glomerata germplasm resources detected by Inter-simple Sequence Repeats (ISSRS) molecular markers. Yi Chuan 28: 1093-1100.

Zhang FM (2001). DCFA 1.1, A Program Companied with AMOVA to Compute the Matrix of Distance. Laboratory of Systematics and Evolutionary Botany, Institute of Botany, Chinese Academy of Sciences, Beijing. 